IP Periodica Polytechnica

Transportation Engineering

46(2), pp. 101-107, 2018

https://doi.org/10.3311/PPtr.10415

Creative Commons Attribution (1)

RESEARCH ARTICLE

\section{Traffic Flow Analysis and Solutions to Ease Traffic Flow at Unsignalized Taxila Intersection}

\author{
Danish Farooq ${ }^{1 *}$, Tayyab Akram²
}

Received 15 December 2016; accepted 18 September 2017

\begin{abstract}
Transportation system of a city affects all aspects of its citizen's economic and personal activities. At a general level, the traffic problem considered as a situation of mismatch between supply (i.e., roads and their capacity) and demands (i.e., travel needs). The city administrators have tried to balance it by creating infrastructures (e.g., new roads, expanding capacity, under pass) or policy changes (e.g., banning heavy traffic movement during peak or day hours). Major problems that motorists are facing on highways intersection are congestion, accidents, and costs. Too many automobiles, trucks, buses, bicycles, and pedestrians are attempting to use the same space to reach their destiny. N-5 (major highway in Pakistan) passes through Taxila where at some intersection extreme traffic congestion sets in. Transportation problems are evident at some locations with complex roadway geometrics. So a traffic study is to be conducted to quantify the extent of transportation problems. This study aims to gain information and understanding about traffic system through the derivation of traffic information from traffic data, and then to apply this information in the assessment of the performance of traffic systems and their interaction with land use activities. This research is an effort to provide suggestion and recommendations to enforce an efficient traffic flow system.
\end{abstract}

\section{Keywords}

congestion, traffic data, traffic flow system, recommendations

\footnotetext{
${ }^{1}$ Department of Transport Technology and Economics,

Faculty of Transportation Engineering and Vehicle Engineering, Budapest University of Technology and Economics,

H-1111 Budapest, Mủegyetem rakpart 3., Hungary

${ }^{2}$ Department of Transportation Engineering,

Faculty of Civil Engineering,

COMSATS Institute of Information Technology,

GT Road, Wah Cantt, Pakistan
}

"Corresponding author, e-mail: farooq.danish@mail.bme.hu

\section{Introduction}

The last few decades have seen a rapid escalation in the number of motor vehicles in the developing countries as a result of various factors such as increase in the purchasing power of common men, the relative reduction in prices and greater availability of used vehicles. It has resulted in greater individual mobility which has caused an increase in congestion.

The National Highway 05 or the N-5 is Pakistan's longest highway running from the port city of Karachi to the border crossing at Torkham. Its total length is $1756 \mathrm{~km}$. It usually consists of heavy transport vehicles. Our study area contains the segment of N5 national highway from U Turn in front of Wah noble company to PSO Petrol Pump $2 \mathrm{~km}$ away on Rawalpindi road.

The location of investigated area was shown in (Fig. 1). It showed that there are so many conflict points for traffic moving in different direction. Drivers encountered problems while turning from one direction to other.

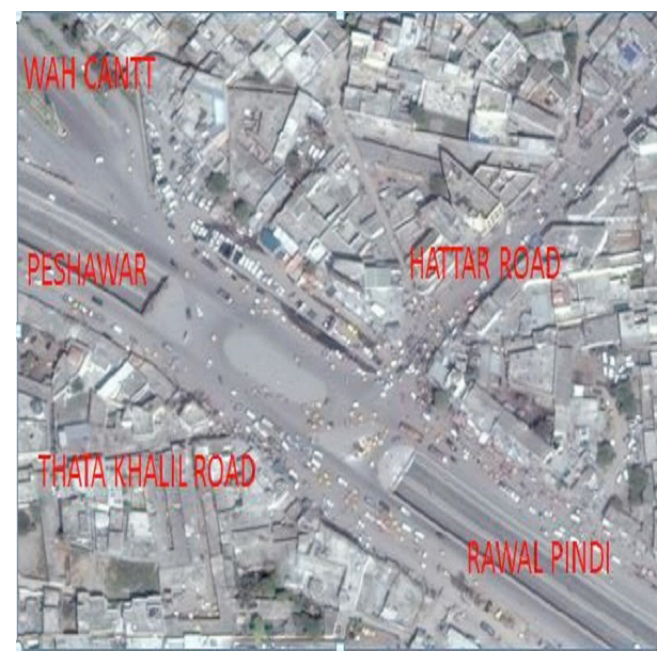

Fig. 1 Location of project

Bus stops, rickshaw stands are not well design on Taxila intersection. The effective width of the road is reduced by illegal parking and vendors marketing. All this leads to a poor traffic condition at this intersection (Fig. 2). The heavy traffic from Hattar industrial estate and some cement factories worsens the situation. The abundance of private vehicles has a large part to play in this 
congestion in addition to heavy traffic. The most obvious result of this congestion is the increase in travel time, especially during peak hours. These factors not only affect the flow of traffic but also affect economy and human health indirectly.

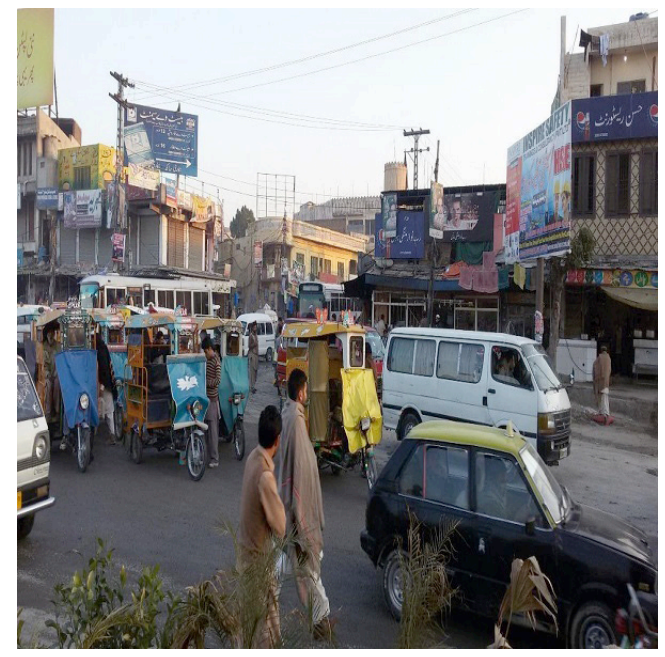

Fig. 2 Traffic congestion situation on Taxila intersection

The techniques of measuring traffic congestion were studied. Conventional "in-situ" technologies such as pneumatic road tubes, piezoelectric sensors and Magnetic loops are employed for traffic count nowadays. Non-intrusive techniques include Manual counts, Passive and active infra-red, Passive magnetic, Microwave radar, Ultrasonic and passive acoustic and video image detection are used worldwide. Most of these techniques are not feasible and economical to be used in Pakistan. For Pakistan the best possible technique is to manually count vehicle using tally sheets or electrical, mechanical counters. Traffic Analysis was conducted on (N-5 Corridor Rawalpindi, Pakistan). This study highlighted difficulties that the road users face on a constant basis while traversing the chosen corridor. This study also includes the identification of measures to mitigate the current predicaments of congestion along the corridor which include less than favourable traffic progression, and an unacceptable level of delays along with the environmental ordeals translated by emissions and noise emanating from the Vehicles (Nasir et al., 2015).

A research based "An Investigation on the Manual Traffic Count Accuracy" was conducted. The research reported in this paper was an empirical observation and quantification of errors in manual traffic counting. Counting errors are small; usually less than $1 \%$.Classification errors are significant, with an average between 4-5\% (Penguin Zhenga and McDonald Mikea, 2012). Simultaneous Travel Model was estimated from survey data and traffic counts. They presented the successful application of a new method to improve travel demand forecasting models by taking advantage of cheap and readily available traffic count data and using them together with household travel survey datato inform the model's parameter estimates (Bernardin et al., 2012).
Peak hour factor presented the time related variation in traffic stream for an hour. All HCM analysis based on peak 15 minutes period within the specific hour means peak hour. If want to apply operational analysis procedure we must convert full hour demand volume to maximum 15 minutes flow rate.

Peak hour can be easily estimated from field data but when field data is not available the assumed values for peak hour factors are 0.88 and 0.92 for rural and urban areas respectively (HCM, 2010).

Research examined traffic congestion particularly in light of increasing public emphasis on the cost of congestion. Traffic behavior and management are discussed in the context of congestion and its various causes. The importance of queues is highlighted. The separate roles of intersections and links are explored (Lay and Maxwell G, 2011).

Traffic congestion is caused by inefficient road operations and by excess demand. Most urban streets and freeways do not have sufficient traffic sensing infrastructure, so one does not know how much congestion there is, its cause, or whether congestion mitigation projects have met the expected improvement. In the absence of adequate information, neither road operators nor travellers can gauge how poorly the road system is operated. The initiatives adopted to overcome traffic congestion would be to shift modes away from private auto, adding bicycle, bus lanes, ridesharing and telecommuting (Kurzhanskiy and Varaiya, 2015).

This paper presented a case study investigating a highly congested intersection in Melbourne. The paper demonstrated various difficulties encountered in the analysis of congestion in practice. The importance of using demand flow data under congested conditions and the impact of queue spillback in reducing saturation flow rates were determined (Yumlu et al., 2014).

In this research safety effects of the unsignalized superstreet countermeasures were determined on existing arterials in North Carolina. The improvements involved traffic flow adjustment, comparison-group, and Empirical Bayes analyses at unsignalized superstreet intersections. The countermeasure indicated that significant reduction in total, angle and left turn, and right turn collisions in all analyses (Ott et al., 2012).

This study illustrated the understanding of traffic simulation model with traffic demand, traffic management and duration of hazard. In reality, required traffic management is useless as the main instructions are unavailable. Well-staged departure and appropriate implementation of traffic management at intersections are recommended, which contribute to extensive distribution of traffic flow and then high-efficiency evacuation (Fu et al., 2014).

The paper presented its interpretations on specificity of road traffic, pedestrian flow interactions, analysis of spatial conflict point formation. The conflict zone creation in the considered conflict was also examined between transport facilities and pedestrians at controlled pedestrian crossings which are located 
in the area of intersections. Methodology developed for accident prediction in accordance with the conflict zone method for various traffic modes at intersections (Kapsky, 2015).

Research was conducted to develop severity distribution functions (SDFs) for ramp segments and unsignalized crossroad ramp terminals for calculating the proportion of crashes in each severity category as a function of roadway geometric design elements. The findings showed that the number of through lanes, barrier presence, area type, and ramp type influenced the high-severity crashes on ramp segments. Furthermore the left-turn operation, access point frequency, the presence of nonramp public street leg, and area type also influenced the proportion of high-severity crashes at crossroad ramp terminals. To obtain more precise estimates of the safety effects these SDFs can be applied along with safety performance functions and crash modification factors for design decisions (Geedipally et al., 2014).

This study sought crosswalks (namely, signalized, unsignalized, and midblock) as complex locations because of the interaction of pedestrians with the vehicle flow. It also identified the importance of pedestrian LOS in the perspective of developing countries, particularly at unprotected midblock crosswalks. To achieve this objective, a review of the literature was carried out which highlighted the need for further pedestrian LOS studies at various facilities under mixed traffic (Kadali and Vedagiri, 2016).

The ICWS (Intersection conflict warning systems) strategy evaluated to reduce the crash frequency by alerting drivers of conflicting vehicles on adjacent approaches at unsignalized intersections. The evaluation used a multistate database of traffic, geometric, and crash data for rural two-way, four-legged, stop-controlled intersections equipped with ICWSs. An empirical Bayes before after analysis was conducted by using safety performance functions (SPFs) for reference groups of similar intersections without installation of ICWS. These SPFs also measured for changes in traffic volumes over time and time trends in crash counts unrelated to the strategy. The aggregate results indicated statistically significant crash reductions at the $5 \%$ level for all crash types for two-lane-at-two-lane intersections and four-lane-at-two-lane intersections (Himes, 2016).

A Low Cost Technique "Indirect Right Turn" was evaluated to Reduce Congestion at Urbanized Intersection in Developing Countries. He utilized low cost "Indirect Right Turn Treatment" to reduce conflicts and congestion at intersections in urban areas. Volume and travel time studies were conducted at three intersections in Islamabad (Kamran, 2011).

Research was made on Plane Intersection Channeling in Traffic Congestion Area. In order to improve the capacity of the plane intersection in the traffic congestion areas, this paper proposed solutions the intersection broadening method in the light of entrance lane broadening, exit ramp broadening, corresponding relation of entrance lane and exit ramp and turning ramp design etc. and also proposed the optimal design method for the traffic (Ye, 2012).

\section{Objectives}

- Measurement of current traffic flow conditions by a manual traffic count survey

- Analysis of traffic flow data

- Causes of congestion

- Suggestion of steps to reduce congestion

- Solutions to remove Conflict points in intersection.

\section{Methodology}

\subsection{Traffic Count Survey}

Manual traffic count was conducted to count the number of vehicle moving in each direction. Vehicles were counted on the basis of their type e.g. bikes; cars, single-axle truck or double-axle trucks etc. were separately counted. As according to our targeted objectives and by literature study peak hour study was conducted. Moreover approach study was conducted rather than turning movement's counts. Vehicles were counted in morning from 07:00 am to 09:00 am and in evening from 04:00 pm to 7:00 pm. Traffic count Performa used in this research was shown in (Table 1).

Table 1 Traffic count Performa

\begin{tabular}{|c|c|c|c|c|c|}
\hline Direction: & From: & & To: & & \\
\hline Period: & Date: & & Day: & & \\
\hline \multirow{3}{*}{$\begin{array}{l}\text { Time } \\
\text { (minutes) }\end{array}$} & & All C & ategories & & \\
\hline & $\begin{array}{l}\text { Motor } \\
\text { Bikes }\end{array}$ & $\begin{array}{l}\text { Car/Jeep/Taxi/ } \\
\text { Pickup/Rickshaw }\end{array}$ & $\begin{array}{l}\text { Heavy } \\
\text { vehicle }\end{array}$ & Tractor & \multirow[t]{2}{*}{ Total } \\
\hline & 1 & 2 & 3 & 4 & \\
\hline \multicolumn{6}{|l|}{0 to 15} \\
\hline \multicolumn{6}{|l|}{15 to 30} \\
\hline \multicolumn{6}{|l|}{30 to 45} \\
\hline \multicolumn{6}{|l|}{45 to 60} \\
\hline Total & & & & & \\
\hline
\end{tabular}

\subsection{Buses and Wagons Count}

All Bus stands are not well planned so that's why everyone has its desired place to stand. Due to lack of practice of enforcement agencies on intersection drivers drop the passengers in center of intersection causing problems and frustration for drivers coming behind them. Taxi stand, Talagang, Swabi, Mardan, Rawalpindi, Sadr and HMC Stands are being operated on service road along N-5 (SB). The numbers of registered vehicles that pay toll on daily basis on each temporary bus stand were counted as shown (Table 2).

\section{Results and Discussions}

After collecting the traffic data for each road; Flow rate, Capacity, Maximum Service flow rate, volume to capacity ratio and Level of service was calculated for intersection. 
Table 2 Bus and wagon counts on vehicle stands

\begin{tabular}{lll}
\hline No. & Vehicle Stand & No. of Vehicles \\
\hline 1 & Talagang & 10 \\
2 & Swabi & 15 \\
3 & Mardan & 16 \\
4 & HMC & 13 \\
5 & Khanpur & 22 \\
6 & Peshawar & 11 \\
8 & Saddar & 15 \\
9 & Haripur & 15 \\
10 & Chakwal & 13 \\
11 & Taxi Stand & 25 \\
12 & Rickshaw & 900 \\
\hline
\end{tabular}

\subsection{Passenger Car Equivalent (P.C.E)}

Passenger Car Equivalent (PCE) is a metric unit used in transportation, to assess traffic Flow rate on a highway. A Passenger Car Equivalent is essentially the impact that a mode of transport has on traffic variables (such as headway, speed, density) compared to a single car. Highway capacity is measured in PCE/hour daily. Passenger Car Equivalent is also sometimes used interchangeably with Passenger car unit (PCU).A common method used in the USA is the density method. However, the PCU values derived from the density method are based on underlying homogeneous traffic concepts such as strict lane discipline, car following and a vehicle fleet that does not vary greatly in width. According to HCM (Highway Capacity Manual), the values of P.C.E for different vehicles were listed (Table 3).

Table 3 Passenger car equivalent (PCE) values

\begin{tabular}{lll}
\hline No. & Vehicle Type & P.C.E. \\
\hline 1 & Animal Driven Cart & 4 \\
2 & Motor Cycle/Rickshaw & 0.5 \\
3 & Bicycle & 0.2 \\
4 & Passenger Car/ Jeep & 1 \\
5 & Large Bus & 3.5 \\
6 & Hiace/Coaster & 3 \\
7 & 2-Axle Truck & 4 \\
8 & 3-Axle Truck & 5 \\
9 & Long Vehical & 6 \\
10 & Tractor Trolly & 4 \\
\hline
\end{tabular}

\subsection{Level of Service}

Level of service was measured by calculating volume to capacity ratio using HCM 2000 (Highway Capacity Manual). The level of service description and limitations listed below.

A: $\quad$ Free-flow conditions with unimpeded maneuverability. Speed delay at signalized intersection is minimal (0.00 to 0.60$)$.
B: Reasonably unimpeded operations with slightly restricted manoeuvrability. Stopped delays are not bothersome (0.61 to 0.70$)$.

C: $\quad$ Stable operations with somewhat more restrictions in making mid-block lane changes than LOS B. Motorist will experience appreciable tension while driving (0.71 to 0.80$)$.

D: Approaching unstable operations where small increases in volume produce substantial increases in delay and decreases in speed (0.81 to 0.90$)$.

E: Operation with significant intersection approach delays and low average speeds (0.91 to 1.00 ).

F: Operation with extremely low speeds caused by intersection congestion, high delay and adverse signal progression (Greater than 1.00).

The level of service was observed "E" Or " $F$ " on intersection in the morning and evening times as shown (Table 4 and Table 5). Especially in evening intersection has failed to fulfill the flow demands because demand exceeds capacity as LOS is "F". Volume of heavy vehicles especially trucks increases in evening. On average, one truck entering intersection in every one minute but takes more than a minute to leave the intersection because of slow moving traffic stream and also it takes more time during turning. Moreover illegal Rickshaw parking has restricted the turning radius for trucks and other heavy vehicles. Also heavily loaded trucks have damaged the pavement at entrance of HMC road which slows down traffic and results in congestion.

Table 4 LOS on intersection in morning

\begin{tabular}{cccccccc}
\hline \multicolumn{3}{c}{ Towards Intersection } & \multicolumn{4}{c}{ From Intersection } \\
\hline PHF & MSF & V/C & LOS & PHF & MSF & V/C & LOS \\
0.98 & 4448 & 0.71 & C & 0.87 & 5496 & 0.98 & E \\
\hline \multicolumn{1}{c}{ Table 5 LOS on intersection in evening } \\
\hline \multicolumn{1}{c}{ Towards Intersection } & \multicolumn{3}{c}{ From Intersection } \\
\hline PHF & MSF & V/C & LOS & PHF & MSF & V/C & LOS \\
0.90 & 6060 & 1.05 & F & 0.88 & 7764 & 1.3 & F \\
\hline
\end{tabular}

\section{Solutions}

After analysis of the traffic data and observing the functional performance of the intersection different solutions were proposed on projected area to ease traffic flow on Taxila intersection described here one by one.

\subsection{Flyovers}

Flyovers are ultimate solutions in order to minimize the congestion because we do not have enough space at intersection for any other solution. Two flyovers were designed on eastern and western side along with specifications (Fig. 3). Eastern flyover will accommodate the traffic moving towards Peshawar and 
Thatha Khalil while western flyover will accommodate the traffic moving towards Wah Cantt, Gulistan and HMC. Flyovers will reduce the time of travelling and also the chances of accidents.

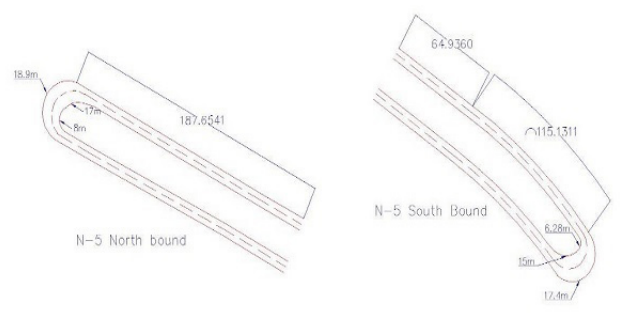

Fig. 3 Proposed flyovers

\subsection{Bus Stand and Bus Stops}

A new Bus stand has been proposed in which all above mentioned bus stops will be there. New bus stand will provide easiness for passengers by providing all bus stands at one place. The new bus stand proposed in the available space in front of Roylson Hotel at reduced distance 0+740 (From the beginning of project on NB) as shown (Fig. 4). Bus stand has an area of $9152 \mathrm{~m}^{2}$. Bus stops are also provided for the vehicle which wants to stay for short time (Fig. 4) but if the drivers wants to stay for long time it is recommended to stay in Bus stand. Presence of bus stops shelter would force the drivers and passengers only to wait at bus shelter.

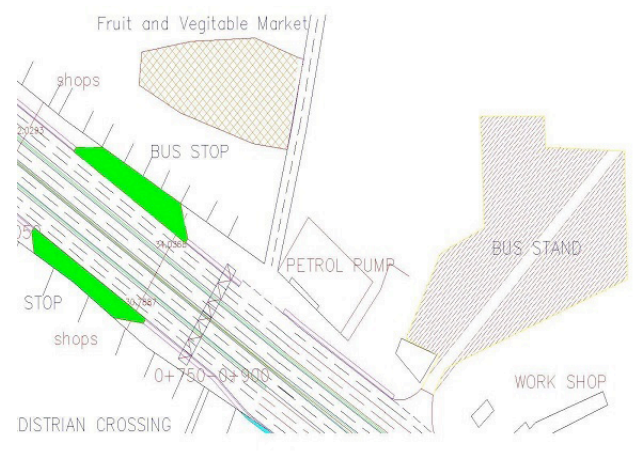

Fig. 4 Proposed bus stand and bus stops

\subsection{Rickshaw stands}

Rickshaw stands have been proposed separately for all direction (Fig. 5). On which every Rickshaw will be registered and will follow schedule of movement towards its destination. Rickshaw stand for HMC proposed on service road on left of N-5 south bound $(1+150)$. Rickshaw stand for Margalla proposed along bus stop for the traffic moving towards Rawalpindi (SB). Rickshaw stand for Basti will be available near bus stop $(1+050)$ for traffic moving towards Peshawar.

\subsection{Pedestrian crossing}

Pedestrians are one of the reasons that make the traffic stream slow. Most crashes occur when pedestrians try to cross the road without traffic rules. Pedestrian crossings were proposed between bus stops on NB and SB as shown (Fig.6a and 6b). By providing the pedestrians crossings at these locations will accommodate the passengers for moving towards bus stand also it will force automatically passengers to use bus stop which is not in use nowadays. Another advantage will be that proposed pedestrian crossings at these locations will be close to fruit market and bus stops.

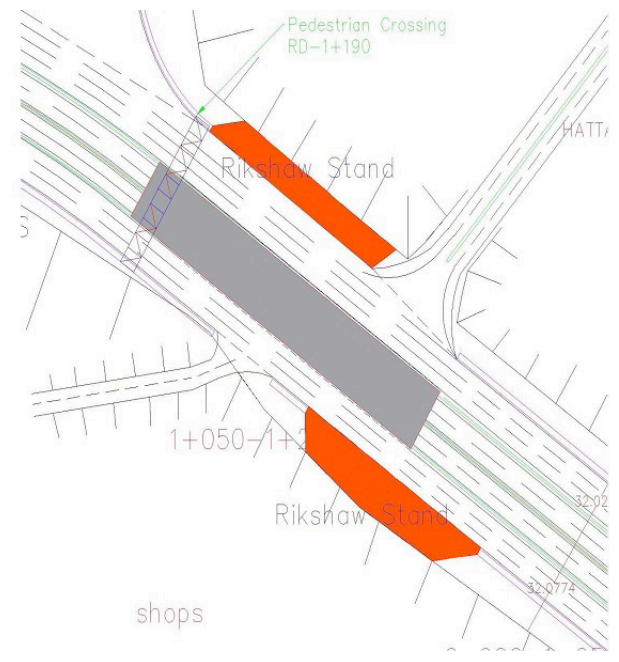

Fig. 5 Proposed rickshaw stands

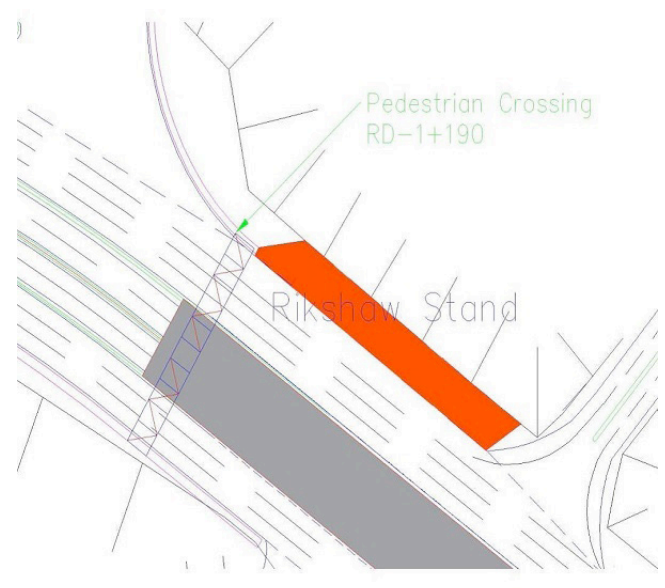

(a)

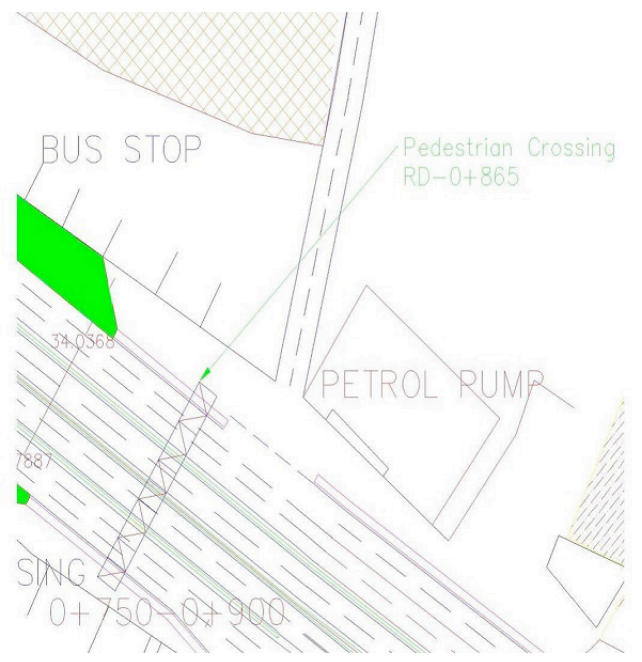

(b)

Fig. 6 Proposed pedestrian overhead bridge 


\subsection{Proposed Truck Rout}

To minimize congestion a solution needed to be proposed to reduce the heavy traffic on this intersection so an alternative route was proposed joining Hattar road and N-125 road via "canal road" (Fig. 7). Heavy traffic on Hattar road will be diverted towards $\mathrm{N}-125$ road via canal road. Tucks will use this proposed route from 6 am to $8 \mathrm{pm}$. At night $8 \mathrm{pm}$ to 6 am trucks can use HMC road in order to assure the safety of Trucks and Drivers because proposed route is dangerous at night due to very low traffic. This will reduce the volume of heavy traffic coming to the intersection in day timings.

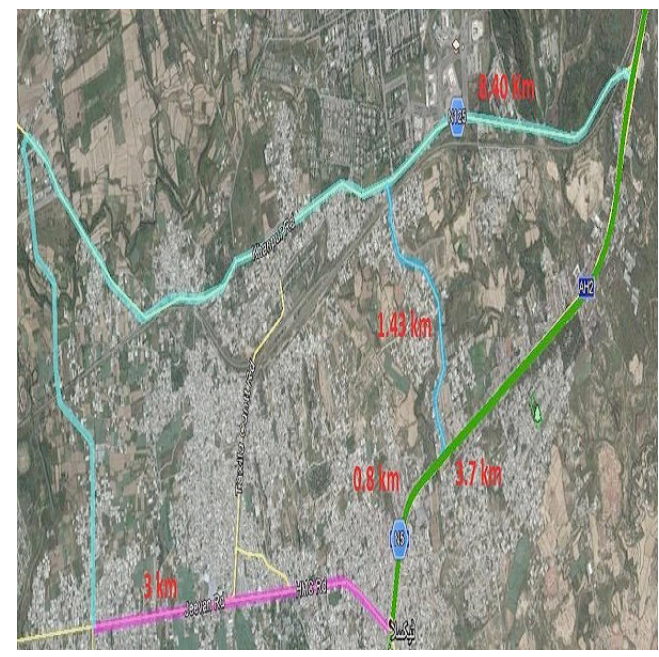

Fig. 7 Proposed truck route

\subsection{Fruit and Vegetable Market}

One of the major reasons of congestion on the intersection is the fruit and vegetable vendors on the road side. The proposed market has an area of 3520 sq. meters (Fig. 8). It will be enough to accommodate all the vendors near the intersection. We have proposed fruit and vegetable market near intersection. It has an area of $3528 \mathrm{~m}^{2}$ located at $0+840$ just near bus stop. All vendors who have setup their stalls and carts in travelled way will set their business in proposed market. All vendors in one place would help administrative authorities to manage safety and price control.

\section{Conclusions}

These proposed solutions will ease traffic flow on Taxila intersection having following features:

- Reduce congestion

- Minimize delay time

- Increase mobility

- Remove traffic conflicts

- Reduce accident rates

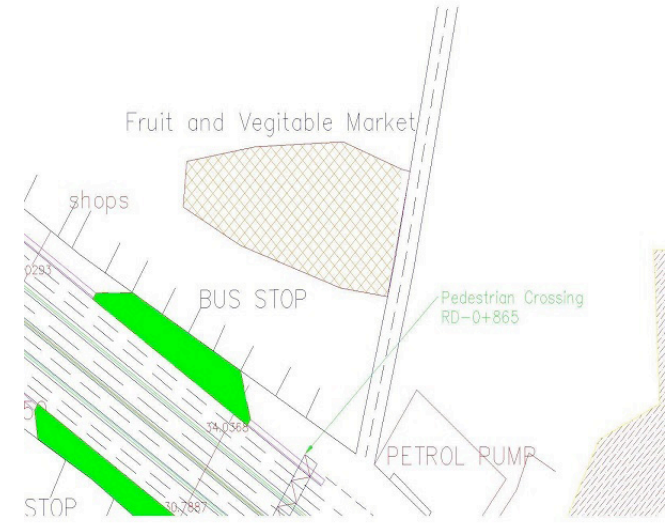

Fig. 8 Proposed fruit and vegetable market

\section{References}

AASHTO. (2004). A Policy on geometric design of highways and streets. 5th edition, Washington, D.C.

Bernardin, Jr. V. L., Trevino, S., Slater, G., Gliebe, J. (2012). Simultaneous Travel Model Estimation from Survey Data and Traffic Counts. Transportation Research Record: Journal of the Transportation Research Board. 2494, pp. 69-76. https://doi.org/10.3141/2494-08

Botha, J. L., Edward, C. Sullivan., \& X. Zeng. (1992). Level of service of twolane rural highways with design speeds less than $60 \mathrm{mph}$. Final reports, vols. 1 and 2,California Department of Transportation, Sacramento, June 1993

Federal Highway Administration. (2007). What are the safety features of active traffic management: U.S. Department of Transportation. M 42 Jct 3a - Jct 7.

FHWA. (2001). Manual on uniform traffic control devices: millennium edition. U.S. Department of Transportation, Washington.

Fu, H., Pel, A. J., Hoogendoorn, S. P. (2015). Optimization of evacuation traffic management with intersection control constraints. IEEE Transactions on Intelligent Transportation Systems. 16(1), pp. 376-386. https://doi.org/10.1109/TITS.2014.2336266

Geedipally, S., Bonneson, J., Pratt, M., Lord, D. (2014). Analysis of injury severity in crashes on ramps and at crossroad ramp terminals. Transportation Research Record: Journal of the Transportation Research Board. 2435, pp. 37-44.

https://doi.org/10.3141/2435-05

Himes, S., Gross, F., Eccles, K., Persaud, B. (2016). Multistate safety evaluation of intersection conflict warning systems. Transportation Research Record: Journal of the Transportation Research Board. 2583, pp. 8-16. https://doi.org/10.3141/2583-02

Kadali, B. R., Vedagiri, P. (2016). Review of pedestrian level of service perspective in developing countries. Transportation Research Record: Journal of the Transportation Research Board. 2581, pp. 37-47.

https://doi.org/10.3141/2581-05

Kamran, A. (2011). Cost technique "indirect right turn" to reduce congestion at urbanized signalized intersection in developing countries. Procedia Social and Behavioral Sciences. 16, pp. 568-577. https://doi.org/10.1016/j.sbspro.2011.04.477

Kapsky, D., Pegin, Р. (2015). МЕТОДИКА ПРОГНОЗИРОВАНИЯ АВАРИЙНОСТИ ПО МЕТОДУ КОНФЛИКТНЫХ ЗОН В КОНФЛИКТЕ «ТРАНЗИТНЫЙ ТРАНСПОРТ-ПЕШЕХОД» НА ОСНОВЕ МОДЕЛЕЙ ДВИЖЕНИЯ НА РЕГУЛИРУЕМОМ ПЕРЕКРЕСТКЕ. (Accident prediction methodology using conflict zone method for "transit transport - pedestrian" conflict situation and models of traffic flows at controlled intersection.), Science and Technique. 5, pp. 46-52. (in Russian) 
Kurzhanskiy, A. A ., Varaiya, P. (2015). Traffic management: An Outlook. Economics of Transportation. 4(3), pp. 135-146. https://doi.org/10.1016/j.ecotra.2015.03.002

Lay, M. G. (2011). Measuring Traffic Congestion. Road and Transport Research. 20(2), pp. 50-61

Nasir, A., Ahsan, A., Saim, R., Rana, J. M. (2015). Traffic analysis of case study (n-5 corridor rawalpindi, pakistan). European Academic Research. 3(4), pp. 4945-4956.

Ott, S. E., Haley, R. L., Hummer, J. E., Foyle, R. S., Cunningham, C. M. (2012). Safety effects of unsignalized superstreets in North Carolina. Accident Analysis and Prevention. 45, pp. 572-579.

https://doi.org/10.1016/j.aap.2011.09.010
Ye, B. (2012). Plane Intersection Channeling in Traffic Congestion Area. Journal of Ningbo University of Technology. [Online]. Available from: http://en.cnki.com.cn/Article_en/CJFDTOTAL-LBGS201203016.htm [Accessed: 19th September 2017].

Yumlu, C., Moridpour, S., Akcelik, R. (2014). Traffic congestion in Melbourne, Australia. A case study. In: Paper presented at the AIPM 2014 national conference, Adelaide, Australia.

Zheng, P. J., Mcdonald, M. (2012). An Investigation on the Manual Traffic Count Accuracy. Procedia - Social and Behavioral Sciences. 43, pp. 226-231. https://doi.org/10.1016/j.sbspro.2012.04.095 